\title{
Arab American Adolescents' Responses to Perceived Discrimination: A Phenomenological Study
}

\author{
Danielle Balaghi*, Evelyn R. Oka ${ }^{\dagger}$, and Dorinda Carter Andrews ${ }^{\ddagger}$
}

Discrimination is a chronic issue in the United States. Arab American Muslims are one group that has experienced an increase in discrimination in recent decades. This study aimed to highlight the lived experiences of Arab American adolescents' perceived discrimination as it relates to their coping experiences. The sample comprises ten (female $=5$; male $=$ 5) Arab American Muslim-identified youth between the ages of 13 and 17. Participants were recruited using purposive sampling. Using a phenomenological approach, data were collected using semi-structured individual interviews and online journal writing. Validity was assessed via member checks and data triangulation using multiple participants and sources. The data were analyzed using interpretive phenomenological analysis, guided by Risk and Resilience Theory and Critical Race Theory. The results revealed three positive and three negative ways that participants coped with perceived discrimination. Understanding how adolescents respond suggests ways to foster their psychological wellbeing by promoting positive responses to discrimination while also helping youth to recognize negative responses.

$$
\begin{gathered}
\text { Keywords } \\
\text { psychological well-being } • \text { Arab American • racial discrimination }
\end{gathered}
$$

\section{Introduction}

Racial and ethnic discrimination is ubiquitous in the United States. For Arab Americans, discrimination has been pervasive, with about 41\% reporting experiences of discrimination in 2010 (Pew, 2017). There has also been an increase in awareness of religious discrimination with about

*Michigan School of Psychology, dbalaghi@msp.edu

(1) https://orcid.org/0000-0003-2262-3826

${ }^{\dagger}$ Michigan State University, evoka@msu.ed

${ }^{\ddagger}$ Michigan State University, dcarter@msu.edu

(D) https://orcid.org/0000-0002-2632-8368

Correspondence concerning this article should be addressed to Danielle Balaghi, Michigan School of Psychology, 26811 Orchard Lake Rd, Farmington Hills, MI 48334.

doi: $10.3998 / \mathrm{jmmh} .131$

Conflicts of interest:

The authors have no conflicts of interest to disclose. 
82\% of Americans perceiving that Muslims experience discrimination (Pew, 2017). Since 2015, Hate crimes against Muslims have increased 197\% (SPLC, 2017). Arab American Muslims are particularly vulnerable, being targeted for their ethnicity and religion. Research has indicated that Arab American Muslims experience more discrimination than Arab American Christians (Abuelezam et al., 2018), underscoring Arab American Muslims' “double minority" status in the United States.

Currently, there are 3.5 million Arab Americans in the United States (Arab American Institute, 2017), which increases the likelihood of psychologists encountering Arab American Mus$\mathrm{lim}$ adolescents in their professional settings. Arab Americans come from a variety of countries and vary in their religious affiliation. Most Arab Americans have origins in Lebanon and Syria and live across many states (Arab American Institute Foundation, 2012). Additionally, although most Arabs outside the U.S. are Muslim, the majority of Arab Americans are not Muslim. Contrary to popular belief, 63\% of Arab Americans identify as Christians, 24\% as Muslim, and 13\% identify as "other" (i.e., Jews, Hindus, etc.; Haboush, 2007; Mason, 2018). Understanding the differences between Arab Americans and Muslim Americans can be critical for understanding the relations between perceived discrimination, wellbeing, and coping. Origins for most Muslim Americans also differ from Arab Americans, which include historically African lineage via the Black American population, Pakistan, India, Iran, Indonesia, and more recent African immigrants. Most Muslim Americans are South Asian, accounting for 35\% of the Muslim American population. Acculturation processes may also differ with about 58\% of Muslim Americans being first-generation Americans and 18\% are second-generation (Pew, 2017); 45\% of Arab Americans are first generation and about $55 \%$ are second generation (American Community Survey, 2019). Lastly, it is important to consider that racial makeup also differs, with $87 \%$ of Arab Americans identified as White, while only 41\% of Muslim Americans generally classified the same, which is significant when considering the interplay between race and discrimination (Benner et al., 2018; Pew, 2017).

Adolescence is a period characterized by significant emotional and behavioral changes, with some adolescents exhibiting greater emotional reactivity and intensity (Steinberg, 2005). Some adolescents exhibit difficulty with emotional regulation, increasing the likelihood of engaging in risky behavior (Casey et al., 2010; Steinberg, 2005). These emotional and behavioral changes could help to understand their reactions to experiences, such as discrimination. For instance, when compared with adults, adolescents may react more intensely to instances of discrimination which may affect their coping experiences (Steinberg, 2005).

When studying perceived discrimination in adolescents, it is not only important to pay attention to the characteristics of the general community in which they reside, but also to the specific contexts within those communities, such as schools, neighborhoods, grocery stores, airports, government offices, etc., as the risk of experiencing discrimination is higher in these shared settings. Studies have investigated discrimination across these social contexts and have found that racial or ethnic minority adolescents perceive most of their discrimination in schools or shops, which is in contrast to racial or ethnic minority adults, who may also perceive discrimination in contexts such as the workplace (Krieger et al., 2006). For instance, for adolescents, school is an important context to consider because research has shown that teachers can hold prejudicial attitudes, beliefs, and values, which can be reflected in their teaching, expectations of students, and/or limited awareness and/or denial of White privilege (Solomona, et al., 2005; Vaught \& Castagno, 2008). Teachers have been found to be unaware of White privilege and to struggle to see how European Americans' cultural values informed the school's culture, atmosphere, policy, beliefs, and expectations (Solomona et al., 2005; Vaught \& Castagno, 2008). For example, discourse analysis of 200 teachers' responses when asked to read McIntosh's (1990) 
seminal article on White privilege, revealed themes such as denying White privilege and believing in a meritocracy (Solomona et al., 2005). For adolescents who spend most of their day in school, psychologists identifying encounters with discrimination within the educational setting could be crucial in understanding Arab American adolescents' experiences with discrimination and its potential effects. Research has shown that children who reported perceptions of discrimination within the school had poorer psychological outcomes and academic achievement that suggested feelings of distrust and powerlessness (Alfaro et al., 2009; Schmitt et al., 2014). This research is robust, showing consistent results across race and ethnicities.

Within the literature, perceived discrimination has been found to be negatively correlated with psychological wellbeing in Arab Americans, corroborating results with African American, Hispanic/Latino, and Asian American samples (Benner et al., 2018; Torres, et al., 2010). Research has found that the greater the level of Arab Americans' perceived discrimination, the lower their self-esteem and overall happiness and the greater their psychological distress (Ahmed et al., 2011). They described having a poor response to stress, a low sense of belonging, and/or limited social resources as potential reasons for why perceived discrimination is negatively related to wellbeing (Abdulrahim et al., 2012; Ahmed et al., 2011; Ajrouch, 2007).

As noted above, Arab Americans who are also Muslim experience the double discrimination of ethnic and religious discrimination. Research has shown that Arab American Muslims are more likely to perceive discrimination than Arab American Christians. For example, Arab Muslim women wearing religious attire like hijab perceive more discrimination (Jasperse et al., 2012). However, while religion can place someone at risk for experiencing discrimination, it can also be a protective factor, buffering against the deleterious effects of discrimination (Ahmed et al., 2011; Stevens et al., 2005). Having high religiosity can provide a person with psychological resources, such as a sense of community, traditions, values, and feeling a sense of belonging, meaningfulness, and purpose (Davis et al., 2003; Jackson \& Bergeman, 2011).

Gender may play an important role in Arab American adolescent experiences of discrimination in the present study. There is some evidence (Ahmed et al., 2011) to suggest that women are less likely to perceive discrimination. Some researchers posit that this is due to women being rooted in their ethnic identity in comparison to males (Al-Harahsheh, 2011; Haboush, 2007). High levels of religious and ethnic identity can provide social supports that buffer the stress from discrimination. These findings raise the question of whether Arab American adolescents may reflect gendered differences in how they experience and respond to discrimination. For instance, it could be that Arab American female Muslim adolescents may be more likely to adhere to traditional gender roles, which may increase the likelihood of identifying with their religion and perceiving discrimination, but this may also provide greater sources of social support.

Responses to adversity can take a variety of forms and can be positive or negative. Youth who have experienced adversities like discrimination may experience negative coping and poorer academic achievement, mental health, and physical health (Byrd \& Carter Andrews, 2016; Flores et al., 2010; Jurcik, 2013; Masten et al., 2004; Perreira et al., 2010). Examples of a negative coping experience is an individual's resigned acceptance of the situation or ignoring discrimination entirely. Either of these strategies can have negative effects on wellbeing (Noh \& Kaspar, 2003).

Other research has shown that in some instances when people face discrimination they may experience positive coping, which may promote resiliency. For instance, people can strengthen their ethnic identity, religiosity, gender identity, social support, and social cohesion, all of which have shown to be protective factors against discrimination (Schwartz \& Unger, 2010; Umaña-Taylor et al., 2015). These resources have been found to promote higher self-esteem, sense of belonging, pride, stability, and social roles (Cohen \& Wills, 1985; 
Echeverría et al., 2008; Phinney \& Flores, 2002). Second, they may engage in other positive coping strategies that are goal-oriented behaviors, such as engaging in activism, seeking out social support, and problem-solving, which are also associated with a greater likelihood of resiliency (Noh \& Kaspar, 2003).

There is some research showing that positive and negative experiences of coping are related to a person's meaning-making of a stressful situation (Folkman \& Moskowitz, 2000). For instance, those who engaged in positive reframing, such as perceiving discrimination as a collective struggle, were more likely to have positive coping experiences and greater likelihood of resiliency (Wexler et al., 2009). This is because positive meaning-making provides a person with a multitude of psychological resources, such as self-efficacy or better problem-solving (Folkman \& Moskowitz, 2000). Those who experienced negative meaning-making tended to perceive discrimination as a threat or harm to their personal identity, collective identity, and/or physical environment (Rogers et al., 2012; Wexler et al., 2009). This type of meaning-making does not provide a person with psychological resources and may in fact contribute to learned helplessness and poor wellbeing (Schmitt et al., 2014).

The goal of the current study is to examine how Arab American Muslim adolescents respond to and cope with perceived discrimination. Specifically, the study aimed to answer the following question: How do Arab American Muslim adolescents experience coping with perceived discrimination?

\section{Sociocultural and Resiliency Considerations}

Two frameworks, Risk and Resiliency Theory (RR; Masten, 2001) and Critical Race Theory (CRT; Delgado, \& Stefancic, 2017), informed the examination of the research question. Within $\mathrm{RR}$, resilience has been defined as " ... good outcomes despite serious threats to adaptation to development" (Masten, 2001, p. 228). RR defines risks as hazards that threaten a person's development and wellbeing, such as low socioeconomic status, maltreatment, community violence, war, divorce, etc. (Masten, 2001). This study used RR as a framework for examining the risk and protective factors that may play a role in Arab American adolescents' wellbeing. Within this study, discrimination is considered a risk factor, whereas religiosity and ethnic identity are viewed as protective factors for wellbeing and resiliency. Perceived discrimination, has been found to be associated with negative psychological functioning such as depression, poor self-esteem, and externalizing behaviors (Benner et al., 2018).

Critical Race Theory (CRT) aims to understand how race, racism, and power relate and interact within American society (Delgado, \& Stefancic, 2001). In general, CRT theorists are guided by the following six tenets: racism is ubiquitous in the lives of ethnic minorities; racism is maintained due to material determinism or interest convergence (where the dominant group has little reason to change the status quo unless it benefits them); race is socially constructed; differential racialization (the dominant group racializes specific minority groups to fulfill their needs); intersectionality (people of color can experience discrimination based on multiple targeted identities simultaneously); anti-essentialism (to avoid a one-size-fits-all in research for a particular racial or ethnic group); and that racial or ethnic minorities have a unique voice (i.e., unique perspective) that needs to be seen as valid and accepted as legitimate. CRT informed the development of this study's research questions, literature review, methodology, and analysis by directing our focus on racial or ethnic social construction, racism as ubiquitous in our social context, and intersectionality. These CRT tenets are relevant and appropriate for the current study because Arab Americans may be racialized as people of color (Kayyali, 2013) despite their legal classification as being White. The majority of the first wave of Arab American immigrants were 
Christian (Abdulrahim et al., 2012; Haiek, 2010). As the sociopolitical climate changed over the past 50 years, Arab Americans have become equated with Muslims, "othered", and racialized. In the later decades of the $20^{\text {th }}$ century, anti-Arab and anti-Muslim sentiment escalated due to the Arab-Israeli conflict, oil conflicts, and problems with Iran and reflected shifts in U.S. sociopolitical climate and policy (Kayyali, 2013). With the increasing sociopolitical hostility today, Arab Americans continue to be racialized, resulting in a distinctly different experience than their non-Arab White counterparts.

Although the racial minority status is still being debated, there does seem to be a consensus across organizations, including the Arab American Institute, that Arab-Americans should be perceived as a specific ethnic minority group (Kayyali, 2013). Even though the census does not identify Middle Eastern/North African (MENA) origins as a separate category, many in the MENA community still advocate for their own, because they believe that Arab American numbers and concerns are undervalued as a result.

\section{Method}

\section{Research Design Overview}

A phenomenological approach is often used by researchers to better understand both the objective experiences that the participants have in common (i.e., "essential" features of a phenomenon) and the subjective experiences unique to each participant. A phenomenological approach was used in this study to better identify objective experiences common to Arab American adolescents as a group, while also examining the subjective experiences of each adolescent. This approach provides researchers with a better understanding of how race, racism, and resiliency are interconnected both across and within Arab American adolescents daily lived experiences. The study was approved by the Michigan State University Institutional Review Board (IRB).

\section{Study Participants}

The sample consisted of ten Arab American adolescents (five female and five male) living in an ethnic enclave. All 10 participants identified as Muslim $(n=10)$, and of the five female participants, two female participants wore hijab. All ten participants were U.S. citizens who reside in the Midwest. Nine out of ten participants were born in the United States, ages ranging from 13 to 16 , with the average age being 14 years old. All participants identified as White. The majority of participants were of Lebanese heritage $(n=8)$, and of the remaining participants, one was of Syrian and Turkish descent and the other was of Lebanese and Iraqi descent. Of the adolescents' parents who also participated in the study, eight of the parents were mothers and two parents were fathers. All the parents lived in the ethnic enclave with their children. All of the parent participants were not born in the US $(n=10)$ but were US citizens. Eight of the parents were born in Lebanon, one parent was born in Liberia, and another parent was from Syria.

\section{Participant Recruitment}

This study used purposeful sampling, specifically a snowball sampling strategy (Creswell, 2013). Snowball sampling involves asking community leaders and participants to refer others whom they know to participate in the study (Remler \& Van Ryzin, 2011). Prior to recruitment, the primary author was actively involved within the ethnic community, becoming part of communal activities and attending community meetings, activities, and informal social gatherings. Being involved in the community and attending activities or social gatherings not only reduced 
the "researcher subject" barrier typically found in quantitative studies (Trimble, 2004), but it also increased trust and the likelihood that Arab American adolescents would participate more candidly in the study. In addition, getting involved in the community allowed the primary researcher to observe and interact with community members. Engaging with the community increased theoretical sensitivity (i.e., insight), which helped with the cultural nuances in behavior and language of this population and improve sensitivity to pick up on themes in the data.

Participants were recruited using site-based and individual recruitment techniques (Arcury \& Quandt, 1999). Site-based recruitment occurred in religious centers (mosques and churches), community centers, and social clubs, and in contact with the community leader of those institutions.

Following a similar process, the primary researcher contacted individuals who were informally influential in the community (not necessarily leaders of an organization). Some of these community members were highly active throughout the social and community life of the city and had established extensive social networks. By working together, we collaborated to identify potential participants whom we perceived might be a good fit for the study. On average, data saturation is most likely to be reached with 10 to 14 participants (Creswell, 2013). A participant sample of 10 for this study aligns with typical phenomenological research.

\section{Data Collection}

Prior to the interviews, the primary researcher established rapport with both the adolescents and their parents by disclosing my Arab background and asking rapport-building questions. Data took the form of separate individual interviews with the adolescent and with the parent, and online journals written by the adolescents. The data collection period lasted approximately twelve weeks. For the initial interview, adolescents received a $\$ 10$ gift card to a local store and parents received a $\$ 15$ gift card for their participation. In addition, the adolescents received a $\$ 5$ Visa gift card for completing the journal entry each week. The journal was considered "complete" if the entry demonstrated thorough answers (i.e., three to five sentences for each question). This process continued for six weeks, for up to a total of $\$ 30$ for completing the journal entries. In addition, I emailed or texted them weekly reminders to complete the journal.

Adolescent Interview. Individual, semi-structured, in-person interviews were used to gather in-depth information about discrimination. The interviews covered the following topics: the meaning of being Arab American; general experiences and perceptions with discrimination; discrimination within the community; experiences and perceptions related to discrimination; discrimination within the community specifically against Arab Americans; intersectionality; and responses to discrimination. Examples of questions from the interview protocol include "Have you personally had experiences with discrimination?" and "When you have felt discriminated against, how did you react?" The adolescent interview took about 45 minutes to an hour.

Follow-up Interview. Follow-up interviews with the youth were conducted. The purpose of the follow-up interview was to seek out additional data and clarification of previously collected data. I also engaged in member checking by asking the adolescents to provide feedback on the themes generated and how well the themes accurately represent their experiences. Follow-up questions included, "Could you tell me more about this particular experience with discrimination?" and "What did you mean by

?". The follow-up interview took about 45 minutes.

Journal. Adolescents were asked to keep an online journal about their experiences with discrimination. Each participant received a link to a university-based online drive, a secure website that allows documents to be shared online. The participants accessed this secure website with an email account that was created for them using random user ids. To maintain 
confidentiality, each participant was allowed to choose a pseudonym to use when writing in the journal. The journal was labeled as "Week 1/First Entry," with a date that indicated the start and end of the data collection for that week. Contact information for the researcher was provided in the upper right-hand side of each page of the journal. Prompts were provided on each page and the adolescent was instructed to respond underneath each prompt. An example of a prompt included, "Over this past week, were there experiences that made you feel good/ happy/proud? To be an Arab American?” It was expected that the journal would be accessible for six weeks.

The participants were asked to respond to specific prompts at least once a week. The adolescents had the option to audio record their answers to the prompts and input them into the document through an app called "Voice Comments," which was installed into their online journal. Although this was available for everyone, it was especially helpful if participants had trouble with written expression or communication. The journal was shared with me using a dedicated email address for this purpose. I reviewed the journal entries at the end of each week on Saturday. In addition, at the end of the week, with the permission of the parent, I either called, met via video conference with the adolescent, or had a dialogue within the journal (e.g., write clarifying questions/comments or engage in the chat function) to discuss their responses to the prompts.

Parent Interview. Similar to the adolescent interviews, an in-person, semi-structured, interview was used to gather in-depth information about parents' experiences with discrimination and their perception of their children's experience with discrimination. Sample questions from the interview protocol include, "Have you ever experienced a situation (online or in-person), where you felt disrespected, put down, or told that you don't belong because you are Arab American?" and "Has your son/daughter personally had experiences with discrimination?". The parent interview questions corresponded to the adolescents' interview to maintain consistency between the interviews. The parent interview took about 45. minutes to an hour. The parent's semi-structured interview, while not explicitly discussed in this study, was used for triangulation purposes (collecting and comparing multiple perspectives via multiple data-collection methods).

Demographic Questionnaire. Demographic data was collected from both the adolescents and parents to provide background information to help characterize the participants. The questionnaire asked the participants to indicate the adolescent's age, racial group, ethnic group, national origin, gender, religious identification, and race.

\section{Analysis}

Interpretive Phenomenological Analysis (IPA) was used to analyze the data. IPA is an analytic approach that analyzes participants' lived (social and personal) experiences of a specific phenomenon. IPA has its theoretical underpinnings in phenomenology and in hermeneutics, which views the researcher as interrelated with the research process (Smith \& Osborn, 2007; Smith et al., 2009).

First, I closely read each transcript multiple times and highlighted any statements made by participants that I noted to be of relevance. Then, I engaged in initial coding focusing on semantics, language, and concepts. I wrote these initial codes within the margins. Some codes highlighted concepts, such as "peer support," other codes highlighted language and semantics, such as "American" equating to "White".

Within each transcript, I started to look for relationships among the codes generated, creating emergent themes. For instance, the codes "showing concern from friends," "acceptance from friends," "felt cared for by friends," or "getting a ride home from friends" fell into the 
emergent theme of "peer support". I wrote these in separate memos. After the emergent themes were created, I engaged in abstraction, where I looked for interrelationships and connections across the emerging themes. For instance, I collapsed "peer support" and "communal support" into "social support." The next step included cross-case analysis, where I engaged in the same aforementioned process with the rest of the transcripts. Lastly, after analyzing all of the transcripts, I looked for overall patterns in themes and superordinate themes. I wrote down the common themes and superordinate themes that I found across all cases in a memo. Engaging in this strategy allowed me to remain organized and see the "bigger picture." Additionally, I used the strategy of subsumption, where I placed the previous abstracted themes under superordinate themes. For instance, under "positive coping experiences", I placed "social support" and "self-preservation." My theoretical frameworks of RR and CRT were used to help inform the themes and superordinate I created. RR theory provided a conceptual lens that aided in finding themes (and superordinate themes) related to potential positive or negative coping experiences (e.g., social support or resignation, respectively); while CRT helped me deconstruct codes or themes that are associated with discrimination.

\section{Methodological Integrity}

I assessed the validity and trustworthiness of the identified themes using member checking. I met with participants in person to review the themes and asked how well the themes fit with their experiences. The participants agreed with the themes and any additional comments made by the participants were used to supplement the themes. The data were also triangulated by collecting and comparing multiple perspectives using multiple data-collection methods (in-person interviews, journaling, and caregiver interviews). I also used peer debriefing, where two peers of mine helped review my themes and challenge my biases, assumptions, and interpretations via email and in-person. I took the feedback and revised any portions of the study and sent it back to my peers. After a final review, a final manuscript was generated with the agreed upon superordinate themes and subthemes.

\section{Role of the Primary Researcher}

I chose to study the current topic because of my background and personal history as an Arab American who grew up facing a significant amount of discrimination. Growing up in a predominantly White community, I was subjected to multiple forms of discrimination, such as microaggressions (Sue et al., 2007) as well as interpersonal and institutional and ethnic discrimination. These experiences with discrimination can strengthen this research by providing personal insight. Being an Arab American woman has also shaped my values and beliefs in ways that may or may not align with Arab American adolescents in the study. Growing up in a predominantly White community and experiencing discrimination at a young age has also shaped my worldview, which likely contributed to the appeal of CRT as a framework for the current study. In recognition of this, I made diligent efforts to engage in disciplined reflexivity (i.e., reflecting on own personal reactions, biases, assumptions, and worldviews related to the data) by using an autobiographical journal to keep track of personal views and emotions that came up during the research study.

In addition, my coauthors are women of color who bring their own experiences, intellectual frameworks, and theoretical orientations to the data analysis. The second author is an associate professor of school and educational psychology. She identifies as Japanese American. She approaches her work from multicultural and cognitive-developmental theoretical perspectives and operates within a scientist-practitioner framework. The third author is a full professor of 
teacher education. She identifies as Black/African American. She approaches her research using critical race and gender epistemological and theoretical traditions.

\section{Results}

The majority of participants reported experiencing discrimination as part of their daily lives $(n=8)$, highlighting its ubiquity. Contrary to expectations, only three participants reported experiencing religious discrimination. None of these participants, however, discussed using religion to cope with discrimination. What follows is a discussion of the coping strategies and behaviors used by participants when faced with discrimination. Pseudonyms are used to maintain confidentiality of the participants.

\section{Active on Social Media}

A common behavioral experience among participants when faced with certain stressors, like discrimination, was being active on social media. Some behavioral responses facilitated agency and hope. For instance, when Nada was asked to discuss her reaction to instances where she perceived she was being treated unfairly she stated "I express my concern ... I might re-tweet [a video] or something ..." she elaborated stating that her re-tweeting a video or post makes her feel "like I did my part ... trying to get more people aware about whatever it is the tweet was about ... I'm opening people's minds". Other participants also shared information and educated others when perceiving discrimination:

Bassem: ... When I started embracing my culture a lot more and I became very proud of where I was from if I saw something attacking my point of view or my beliefs that's when I would jump in and give my two cents ... Often times I present a logical opinion and often times I present facts [on social media]

Researcher: Related to what?

Bassem: ... related to culture and how people are treated a certain way ... like I recently witnessed a post on twitter about Palestine not being legitimate and you know ... I cracked open books, I went searching through all the files ... [to try to educate] (Interview 1)

Sarah [when asked why she engaged in perceived discriminatory facebook comments]: I only ever engage if I feel ... if they are going to have an educated conversation with you ... and it's kind of in the hope that you can at least change one person's mind ... one person ... leads to two or more ... hate isn't born or taught ... so that one person can have kids and they could raise them to be more accepting or have a different view ... (Interview 1)

Bassem felt empowered to provide information to people online as a way to educate others, which he stated was related to his ethnic pride. Sarah only engaged with people she perceived as open to having an "educated" conversation, possibly implying a conversation that is civil and not emotionally charged. Sarah (just like Nada) perceived those small actions, such as a conversation on social media, can "snowball" to have a larger impact.

\section{Self-Preservation}

Nada and Sarah also coped by engaging in self-preservation responses. Self-preservation was observed in the data as behaviors that protected the self from harm or stress. Both participants 
deleted social media comments or removed themselves from the situation when they perceived the conversation had become toxic. When Nada was asked to discuss a time she was treated unfairly and to describe her reaction to it, she stated:

Nada: Most of the time I'll just delete the first thing I tweeted ... or the first comment I posted ... I'll delete it ... I don't want any more drama or anything ... I just cut it off all together ... (Interview 1$)$

Nada appeared to have felt overwhelmed with the comments she received online that targeted her and her race/ethnicity. Sarah had a similar response to when she perceived toxic behavior from others on social media:

Sarah: Let them think what they want ...'cuz no one is going to win in the end ... if they get too much ... just block them ... there's a block button for a reason. (Interview 1)

Rather than engaging with the comments, both Nada and Sarah either deleted or blocked the people that were engaging in harmful behavior. They did this in attempts to cut off the source of stress, take back control, and protect themselves emotionally and psychologically. For instance, when Sarah was asked if she felt that her voice was being taken away, she said, "No." In fact, she indicated that it was within her control and volition to remove herself from the situation.

\section{Social Support}

Other participants engaged in more straightforward coping skills, such as seeking social support. For instance, Kareem experienced vicarious discrimination by watching a famous YouTuber's video of being escorted off an airplane; when asked how he responded to that experience, he stated that he sought out his brother to help him process:

Kareem [when asked how he felt after talking to his brother]: ... I felt like ... better 'cuz ... I was like oh well that's messed up, I was mad but then I came back to normal ... (Interview 1)

For Kareem, it was a straightforward process, seeking support from a family member when perceiving a form of stress, which produced positive feelings afterwards, indicating that the support was helpful. Celine, who was more prone to resignation, had a similar response when asked how she reacted to being treated unfairly, she stated that she may "talk to another person about it," seeing her friends as a source of support. Alia and Sarah had a similar sentiment, when asked what they liked about spending free time with their friends:

Alia: Like we can be ... ourselves in front of each other even though we are not all the same ... they understand ... like who we are ... they're not usually racist. (Interview 1)

Sara: Yeah ... like if I'm ever in need I have these people ... and it's a feeling a bit of home ... I guess you can say ... it's kind of like ... leaving our little bubble gets a bit scary ... 'cuz you know ... there are people who aren't going to share the ideas that I'm gonna share ... it's a feeling of security [surrounding herself with friends and family]. (Interview 1) 
Sarah highlighted a nuance that indicated that not only was social support conceptualized in terms of support from family and friends but also from the community. She felt like she could rely on the people in her community when faced with stressful events, including discrimination.

\section{Resignation}

Participants spoke about racism as being a "normal, everyday occurrence" in their life and exhibited a feeling of resignation. Mirna highlighted a feeling of resignation and how she has had to change her behaviors because of her experiences with discrimination:

Mirna: It's not frustration ... It's more like ... I've become more apathetic to it ... like I don't even notice that I do it anymore ... I'm almost immune to it now. (Interview 1)

Celine and Malek had a similar reaction to a discriminatory incident:

Celine: At the end of the day there will always be racist people ... you can't really do anything about it ... it's not worth it ... at the end of the day ... it's their opinion ... no matter what you can't make yourself look worse ... they'll think of you as violent if you react ... so it's better if you make them look bad ... and make yourself look like the better person and a bigger person. (Interview 1 )

Malek: Like I said before ... if you see that one thing going wrong ... you know that there's going to be something [else] bigger and bigger ... [happening] to another thing ... so ... I don't really care. I just know ... things are going down ... it's very bad ... you can't really do anything about it. (Interview 1)

Celine (and other participants that noted feelings of resignation) indicated that not responding generated a heightened negative emotional response including feelings of rejection, regret, helplessness, and sadness. Celine stated, "it hurts ... because ... I really can't do anything to change their mind" (Celine, Interview 1). Although the passive response of resigning was deliberate and had the benefit of preserving their sense of self and their culture, it also came with costs that included a sense of futility.

\section{Humor}

Using humor as a way to cope was more complex. For some, humor helped defend against the negative affect they were experiencing; for others, it was used to diminish the discriminatory event's power. For instance, Sarah used humor when her teacher made a joke about Arab names but felt disappointed by the experience, "we kind of laughed it off ... yeah some names are weird ... but ... they didn't understand they were a bit hurtful" (Sarah, Interview 1). Humor appeared to be used as a way to deflect attention from the "serious matter," as a way to reduce discomfort, at least in the moment. Samer described a similar experience when he watched border patrol agents handcuff his step-father:

Samer: My stepdad in handcuffs. My mom had a break down and I'm like ... why? The guy didn't do anything ... 
Researcher: How did you react ...?

Samer: I found it funny at first, like ... why are you putting him in handcuffs ... there is no point at all ... and then they put them in a separate room ... we didn't know what was back there ... all we heard was this huge yelling and screaming ... and we thought the officer was yelling and screaming at my step dad but it wasn't them it was someone else ... and we aren't treated equally ... not at all. (Interview 1)

Samer laughed because it was, to him, too "ridiculous" of a situation, and laughing appeared to be a way to invalidate discrimination. Humor also appeared to be used to manage the stress of discrimination and cover up any negative affect by deflecting attention away from the discriminatory incident.

Malek: I really don't take things like serious matters seriously. So when taking a serious matter like discrimination ... I kind of joke about it ... and I don't really talk about how others talk about it ... It's sort of a way to deal with it ... So I don't have to speak about it. (Interview 1)

Although humor may have lessened the immediate public discomfort, the participants clearly experienced the encounters as dehumanizing.

\section{Rationalization}

Participants also tried to understand why people would discriminate against them (i.e., rationalizing the other). The participants who rationalized the discrimination cognitively dismissed comments using rationalization. For instance, Bassem was asked how he felt when he experienced hateful comments on social media:

Bassem: The bully is always someone who is being bullied themselves ... so sometimes I feel like it's kinda pathetic that you're coming after me, you probably have your own problems that you should worry about ... (Interview 1)

In this example Bassem rationalized the comments he received on Facebook by naming it as A form of bullying. This was similar to Sarah's responses to an experience she had with her teacher:

Sarah: I mean most I've heard it ... and I don't know if it was meant to be insulting but I had a teacher who ... based off her ignorance ... She's like ... 'I think all you Arabs make up your names ... a bunch of those names can't even be real ... 'cuz if they are there's gotta be a problem with that'. (Interview 1)

Moreover, when being detained for over 17 hours (for no disclosed reason) by border control agents when crossing the American border by car, Samer, shifted the blame from the agents to national policies on travel:

Samer: Before that man [President Trump] was put in that position, I could go see my cousins whenever I wanted to ... but since I'm ARAB, all the Arabs I seen [sic] got pulled over for like 17 hours ... for no reason. (Interview 1) 
Rather than holding the agents directly responsible, he rationalized the customs agents' behavior by implying that they were acting on orders dictated by the policy, thereby reducing his stress. It appeared that participants' rationalizations for why they were discriminated against had important consequences for their emotions and self-perceptions, as these explanations may have given them something specific to hold responsible, rather than facing an ambiguous and uncertain enemy.

\section{Discussion}

This study attempts to advance our understanding of Arab American Muslim adolescents' experiences of coping with discrimination, providing practitioners and researchers with a snapshot. Most adolescents experienced both positive and negative coping experiences. Positive coping experiences include an active social media presence, self-preservation, and social support, whereas negative coping experiences included resignation, humor, and rationalization. Some research has highlighted that coping is flexible and fluid, especially with people who experience chronic stress (Gignac \& Gottlieb, 1997), which may include discrimination. Adolescents in this study showed that in the face of a chronic stressor, such as discrimination, they often had both positive and negative coping experiences, depending on how they appraised the specific discriminatory event.

Positive coping experiences (i.e., religion, active presence on social media, self-preservation, and social support) facilitated psychological resources that promote resiliency. Participants active on social media may have played a positive role with their sense of agency, ethnic pride, self-efficacy, and empowerment. Self-preservation appeared to provide a sense of control and volition, and social support provided a sense of belonging, emotional support, and instrumental support. These psychological resources have been linked to better psychological wellbeing and resiliency in the face of stress (Masten et al., 2004; Tugade et al., 2004). While speculative, these experiences and psychological resources may be related to how the adolescents understood themselves in relation to discrimination. With adolescence being a time for identity exploration and growth, it is also a time when they are starting to cultivate their own worldview and beliefs as they relate to their sense of self (Berk, 2010). They are also trying to determine and prioritize what is personally significant to them. How an Arab American adolescent experiences coping may be related to their meaning-making of a perceived discriminatory experience. There is some research to support those individuals who find positive meaning in a situation have a better array of resources, such as better mood, problem-solving abilities, and self-efficacy (Folkman \& Moskowitz, 2000). These psychological resources were also present in participants' coping experiences. For those who experienced positive coping experiences, some participants, such as Nada and Sarah, perceived discriminatory experiences as not only at odds with their beliefs and values, but also reaffirmed their belief in their ability to foster social change. They perceived themselves as having a more active role in society. For instance, sharing posts related to discrimination appeared to promote a sense of agency in facilitating change by raising awareness, educating others, and advocating for social justice (e.g., by "opening people minds"), which may also result in positive affect (i.e., "feeling good"). Another example was seen through their self-preservation experience, which reflected a sense of control and volition (i.e., " ... because I made the choice to delete it"). Self-determination theory has noted that people like to feel in control because competency and autonomy fulfill two basic needs necessary for psychological stability and growth, (Deci \& Ryan, 2004; Skinner \& Edge, 2002). People striving for a sense 
of control may be striving to feel efficacious in their ability to navigate their social environment and to feel responsible for their own actions. Research has shown that have a sense of control fulfills these needs, which in turn motivates them to engage in adaptive coping strategies, such as problem-solving (Cheng et al., 2013; Ntoumanis et al., 2009). Lastly, social support promoted positive affect and sense of stability (i.e., "I felt like ... better 'cuz like ... I was like oh well that's messed up, I was mad but then I came back to normal"), which can not only lead to better wellbeing but can buffer against discrimination (Cohen \&Wills, 1985).

For negative experiences of coping (i.e., resignation, humor, and rationalization), adolescents may have made meaning out of discrimination differently. Participants who tended to have more negative coping experiences also tended to perceive discrimination as more of a threat to their sense of self, culture, and community. Additionally, some of these participants perceived their role in society as more passive and avoided stressful situations. For resignation, while at odds with their beliefs and values, participants perceived discrimination as normal and embedded in society. They viewed themselves as having little power or control to change something that is ubiquitous. For instance, Celine often described her experiences in a resigned manner. Her responses highlighted: (1) a belief that prejudice is normal; (2) a sense of powerlessness; and (3) a perceived external locus of control. For Malek, discrimination was nothing "new" or remarkable. Moreover, Malek's comments sometimes indicated a sense of powerlessness through statements, such as, "you can't really do anything about it."

Participants engaged in rationalization when they felt that specific instances of discrimination are not only at odds with their beliefs but felt that their place in the world was diminished by offensive actions or policies. Sarah felt stigmatized by one of her teachers and her comment "I think all you Arabs make up your names ... a bunch of those names can't even be real." Nada felt dehumanized by the negative portrayal of Arabs in the media, which appeared to be culturally accepted; and Samer was aware that he experienced institutional discrimination, as he rationalized and de-personalized his experiences at the border by attributing it to the "Travel Ban." These may have been their attempts at avoiding the reality and stress of discrimination. Some studies have shown that engaging in rationalization is a passive avoidance strategy (Boeschen et al., 2001), where a person avoids the truth or avoids another more threatening explanation for certain behaviors or events.

Humor was another negative coping experience that also appeared to lessen the immediate stress felt from a discriminatory event. Research has shown that humor is a multifaceted trait that can be a healthy or unhealthy form of coping (Chen \& Martin, 2007; Erickson \& Feldstein, 2007). Moreover, unhealthy humor can place an adolescent at risk for stress and poorer wellbeing if used as an avoidance strategy (Erickson \& Feldstein, 2007). Humor appeared to reduce the immediate stress in these situations by deflecting attention away from the discrimination incident (e.g., "It's sort of a way to deal with it ... So I don't have to speak about it"). Although using humor may have lessened the immediate discomfort, the participants clearly experienced the encounters as jarring and disappointing.

\section{Strengths and Limitations}

A key strength of this study is that it offers a discussion with Arab American Muslim adolescents' that gave us a glimpse into their experiences of perceived discrimination at a unique moment in history. During data collection, various sociopolitical events occurred that placed Arab Americans in the national spotlight and in a position where they were being asked to prove their citizenship and patriotism. For example, during the period of interviews, the U.S. launched an air strike against a Syrian airbase (April 6, 2017; Starr \& Diamond, 2017) and 
bombings conducted by ISIS/Daesh in Tanta, Egypt on Palm Sunday left 49 people dead (April 10, 2017; Egypt's Christians, 2017). In the United States, Immigration and Customs Enforcement (ICE) officials detained dozens of Chaldeans and Muslims in Detroit (June 12, 2017; Chaldeans, Muslims detained, 2017), and the "Travel Ban 2.0" was released and overturned by a Federal Judge in Hawaii (June 29, 2017; Totenberg \& Montanro, 2018). Subsequently, however, another travel ban was drafted adding countries, such as North Korea, Venezuela, and Chad, and removing Sudan. After being blocked on October 17, 2017 by two judges, it was upheld by the Supreme Court (Totenberg \& Montanro, 2018). Secondly, while triangulation was also difficult to achieve due to all of the parents reporting that their adolescents did not perceive discrimination, it also highlighted a striking finding. This finding suggested that parents and their children have discrepant views of discrimination experiences. It would be important to follow up with research that examines why this may be the case, whether this is related to generation, acculturation, response bias, parent-child relationships, or other factors. Lastly, while it was not anticipated, having all participants identify as Muslim was helpful to provide a broader, deeper, and nuanced snapshot of religion's relationship to Arab American adolescents' lived experiences with discrimination.

This study has several limitations. One participant was unable to provide much data. Hassan, a 13-year-old Arab American male was highly guarded and described a worldview that is best described as "idealistic". Some research has found that people who perceive that the United States is equal and fair and therefore perceive less discrimination (Pérez et al., 2008).

Another limitation in the study is that while all of the participants spoke about discrimination, the interview questions were racially framed, thus prompting a discussion on racialized experiences. Regardless of the prompting, however, the majority of the participants endorsed experiencing discrimination. Future research should further investigate the nuances of racialization for Arab American adolescents. While this study captures rich data on Arab American adolescent Muslims it does not include the lived experiences of Arab American adolescent Christians and other religious affiliation. Future research should aim at investigating this population, as some research has shown that Arab American Christians experience greater psychological distress when experiencing discrimination (Ahmed et al., 2011). Acculturation proved to be a factor that was not directly considered in this study. Future research should consider incorporating acculturation as a key variable in the study.

\section{Implications}

Psychologists should strive for multicultural competency that includes a clear focus on social justice and equity (Trimble et al., 2014; Wendt et al., 2014). This study revealed that discrimination is prevalent in an Arab American Muslim adolescent's lived experiences. A psychologist must be attuned to their own attitudes and bias towards Arab American Muslims, as it can affect the therapeutic alliance and effectiveness of treatment. The study's findings suggest that it is critical for psychologists to recognize and consider the influence of the sociopolitical climate on mental health, as it can play a multifaceted role in Arab American adolescents' experiences with discrimination and psychological wellbeing. This study highlights the importance of awareness and understanding of how the sociopolitical climate can "seep" into Arab American adolescents' worldviews and contribute to internalized racism. Psychologists should be aware of how current events can shape Arab American adolescents' worldviews and potential internalized racism, when assessing their psychological wellbeing.

Recognizing the prevalence of discrimination, psychologists should be prepared to explicitly acknowledge and discuss racial, ethnic, and religious discrimination in the therapy room, 
as clients are ready, as this can facilitate greater insight and a sense of empowerment for the client. To do this, psychologists should be prepared to discuss important factors related to discrimination. For instance, psychologists should consider age, as adolescents are not only going through a developmental period characterized by significant physical, cognitive, and emotional change (Steinberg, 2005) but are also embedded in specific contexts (such as school) that can place them at greater risk of experiencing discrimination (Krieger et al., 2006). A second factor is religion or spirituality, which could be a protective factor against discrimination (Jackson \& Bergeman, 2011). Psychologists should be open to conversations centered on religion or spirituality and be prepared to suggest religious or spiritual coping strategies as part of treatment with clients for whom religion or spirituality is an important part of their identity.

A third factor is understanding Arab Americans' complex relationship with race. Not only are Arab Americans heterogeneous but those who identify as White may still be racialized within the United States. This study indicated that identifying as White did not protect the adolescents from experiencing discrimination. Thus, if the Arab American adolescent identifies as White, psychologists should not make assume that Arab American adolescents do not experience discrimination. Further, it may be prudent to assess the adolescent's perception of their proximity to Whiteness, Arab American adolescents who perceive themselves as more "distant" from Whiteness or non-White may exhibit greater discrimination (Abdulrahim et al., 2012). Other factors related to discrimination should also be considered, such as such as socioeconomic status (Assari et al., 2018), national origin, gender, acculturation, and the sociopolitical climate, as they can affect the relationship between perceived discrimination and psychological wellbeing (Ahmed et al., 2011; Davis et al., 2003; Hays, 2016).

This study may inform the type of strategies psychologists can use to increase positive coping strategies that foster a sense of agency, particularly among Arab American Muslim adolescents. For instance, promoting involvement with social justice events or helping adolescents become social agents of change may help them develop self-efficacy. Psychologists may use social media to help adolescents learn its tools (e.g.,, self-preservation), seek social support, and engage in sociopolitical movements, all of which may help facilitate resiliency when faced with discrimination. The results may also help shed light on specific forms of negative coping that could be missed. Sometimes humor is seen as a positive emotion-focused coping strategy, failing to see that it is a double-edged sword. Psychologist should stay attuned to the potential function of humor.

CRT is extended by amplifying Arab American Muslim adolescents' voice and narratives. In a society with a tense and polarized sociopolitical climate, providing self-determined narratives may not only provide counter-narratives to mainstream experiences, but may also offer empowerment for social change. CRT underscores the importance of understanding how ubiquitous discrimination is for these adolescents and the constant requirement to adapt and respond. CRT is an important framework to use when studying the risk and resiliency of Arab American adolescents, as it makes their experiences with discrimination central, while deconstructing positivistic notions garnered from etic approaches to research on how Arab American adolescent Muslims experience coping in the face of discrimination. These results also extend the risk and resiliency framework, highlighting that some coping strategies, such as self-preservation, can be adaptive and promote resiliency; whereas some coping strategies, such as humor, can actually be a risk factor. Future research should investigate these coping experiences, and how they can provide adaptive strategies that promote resiliency in the face of various stressors. 


\section{Conclusion}

This qualitative study highlighted how various strategies, such as active presence on social media, self-preservation, and social-support may be protective for adolescents from perceived discrimination's negative effects by providing psychological resources (e.g., self-agency, empowerment, emotional support). This study also indicated that there are some strategies that may not be adaptive, such as resignation, humor, and rationalization, as they can threaten one's sense of self, culture, and community. Arab American adolescents have much to teach us about what it is like to be living in today's United States of America. Their stories revealed how Arab American adolescents' experience coping with discrimination and that these coping experiences are complex and nuanced. These positive and negative coping experiences with discrimination yielded distinctive stories with unique voices that counter the dominant culture's notions and perceptions. The study has highlighted the resilience of its Arab American adolescent participants and their experiences with coping are complex and fluid.

\section{Author Note}

Danielle Balaghi is now at the Department of Psychology, Michigan School of Psychology. This study was funded in part, by Michigan State University Graduate School and Michigan State's College of Education. Correspondence regarding this article should be addressed to Danielle Balaghi, Michigan School of Psychology, 26811 Orchard Lake Rd, Farmington Hills, MI 48334, Email:dbalaghi@msp.edu

\section{References}

Abdulrahim, S., James, S. A., Yamout, R., \& Baker, W. (2012). Racial discrimination and psychological distress: Does Whiteness matter for Arab Americans?. Social science E medicine, 75(12), 2116-2123. https://doi.org/10.1016/j.socscimed.2012.07.030

Abuelezam, N. N., El-Sayed, A. M., \& Galea, S. (2018). The health of Arab Americans in the United States: an updated comprehensive literature review. Frontiers in public Health, 262(6), 1-18. https://doi.org/10.3389/fpubh.2018.00262

Ahmed, S. R., Kia-Keating, M., \& Tsai, K. H. (2011). A structural model of racial discrimination, acculturative stress, and cultural resources among Arab American adolescents. American Journal of Community Psychology, 48(3-4), 181-192. https://doi.org/10.1007/s10464-011-9424-3

Ajrouch, K. J. (2007). Resources and wellbeing among Arab-American elders. Journal of cross cultural gerontology, 22(2), 167-182. https://doi.org/10.1007/s10823-007-9035-5

Arab American Institute Foundation (2012). Quick Facts About Arab Americans. https://b.3cdn.net/aai/ fcc68db3efdd45f613_vim6ii3a7.pdf

Assari, S., Preiser, B., Lankarani, M. M., \& Caldwell, C. H. (2018). Subjective socioeconomic status moderates the association between discrimination and depression in African American Youth. Brain sciences, 8(4), 71-81. https://doi.org/10.3390/brainsci8040071

Benner, A. D., Wang, Y., Shen, Y., Boyle, A. E., Polk, R., \& Cheng, Y. P. (2018). Racial/ethnic discrimination and wellbeing during adolescence: A meta-analytic review. American Psychologist, 73(7), 855-883. https://doi.org/10.1037/amp0000204

Berk, Laura E. (2018). Exploring lifespan development. Pearson. 
Boeschen, L. E., Koss, M. P., Figueredo, A. J., \& Coan, J. A. (2001). Experiential avoidance and post-traumatic stress disorder: A cognitive mediational model of rape recovery. Journal of Aggression, Maltreatment E Trauma, 4(2), 211-245. https://doi.org/10.4324/9780203725276-10

Book, A. S., Volk, A. A., \& Hosker, A. (2012). Adolescent bullying and personality: An adaptive approach. Personality and Individual Differences, 52(2), 218-223. https://doi.org/10.1016/ j.paid.2011.10.028

Boyden, J., \& Mann, G. (2005). Children's risk, resilience, and coping in extreme situations. In M. Ungar (Eds.), Handbook for working with children and youth: Pathways to resilience across cultures and contexts (pp. 3-26). SAGE Publications https://doi.org/10.4135/9781412976312.n1

Brown, A. (2019). Key findings on Americans' vierws of race in 2019. https://www.pewresearch.org/ fact-tank/2019/04/09/key-findings-on-americans-views-of-race-in-2019/

Byrd, C. M., \& Andrews, D. J. C. (2016). Variations in students' perceived reasons for, sources of, and forms of in-school racial discrimination: A latent class analysis. Journal of school psychology, 57(93), 1-14. https://doi.org/10.1016/j.jsp.2016.05.001

Carlson, M. (2014). CBT for chronic pain and psychological wellbeing: a skills training manual integrating $D B T, A C T$, behavioral activation and motivational interviewing. John Wiley \& Sons.

Casey, B. J., \& Jones, R. M. (2010). Neurobiology of the adolescent brain and behavior: implications for substance use disorders. Journal of the American Academy of Child E Adolescent Psychiatry, 49(12), 1189-1201. https://doi.org/10.1016/j.jaac.2010.08.017

Cohen, S., \& Wills, T. A. (1985). Stress, social support, and the buffering hypothesis. Psychological bulletin, 98(2), 310. https://doi.org/10.1037/0033-2909.98.2.310

Córdova, D., \& Cervantes, R. C. (2010). Intergroup and within-group perceived racial discrimination among US-born and foreign-born Latino youth. Hispanic Journal of Behavioral Sciences, 32(2), 259-274. https://doi.org/10.1177/0739986310362371

Chaldeans, Muslims detained by ICE in metro Detroit to be deported. (2017). WXYZ. https://www. wxyz.com/news/dozens-of-chaldeans-muslims-detained-by-ice-in-metro-detroit-to-bedeported

Cheng, C., Cheung, S. F., Chio, J. H. M., \& Chan, M. P. S. (2013). Cultural meaning of perceived control: A meta-analysis of locus of control and psychological symptoms across 18 cultural regions. Psychological bulletin, 139(1), 152-158. https://doi.org/10.1037/a0028596

Deci, E. L., \& Ryan, R. M. (2012). Self-determination theory. In P. A. M. Van Lange, A. W. Kruglanski, \& E. T. Higgins (Eds.), Handbook of theories of social psychology (p. 416-436). Sage Publications Ltd. https://doi.org/10.4135/9781446249215.n21

Delgado, R., \& Stefancic, J. (2017). Critical race theory: An introduction. New York University Press.

Dymond, S., \& Roche, B. (2009). A contemporary behavior analysis of anxiety and avoidance. The Behavior Analyst, 32(1), 7-27. https://doi.org/10.1007/bf03392173

Echeverría, S., Diez-Roux, A. V., Shea, S., Borrell, L. N., \& Jackson, S. (2008). Associations of neighborhood problems and neighborhood social cohesion with mental health and health behaviors: the Multi-Ethnic Study of Atherosclerosis. Health E place, 14(4), 853-865. https://doi. org/10.1016/j.healthplace.2008.01.004

Egypt's Christians mourn 49 killed in Palm Sunday church bombings. (2017). World Watch Monitor. https://www.worldwatchmonitor.org/2017/04/16492/

Gibbons, F. X., O’Hara, R. E., Stock, M. L., Gerrard, M., Weng, C. Y., \& Wills, T. A. (2012). The erosive effects of racism: reduced self-control mediates the relation between perceived racial 
discrimination and substance use in African American adolescents. Journal of personality and social psychology, 102 (5), 1089-1194. https://doi.org/10.1037/a0027404

Folkman, S., \& Moskowitz, J. T. (2000). Positive affect and the other side of coping. American psychologist, 55(6), 647-654. https://doi.org/10.1037/0003-066x.55.6.647

Haiek, J.R., (2010). Arab American Almanac. The New Circle Publishing House.

Hartshorn, K. J. S., Whitbeck, L. B., \& Hoyt, D. R. (2012). Exploring the relationships of perceived discrimination, anger, and aggression among North American indigenous adolescents. Society and Mental Health, 2(1), 53-67. https://doi.org/10.1177/2156869312441185

Hawker, D. S., \& Boulton, M. J. (2000). Twenty years' research on peer victimization and psychosocial maladjustment: A meta-analytic review of cross-sectional studies. The Journal of Child Psychology and Psychiatry and Allied Disciplines, 41(4), 441-455. https://doi.org/10.1111/1469-7610.00629

Hays, P. A. (2016). Addressing cultural complexities in practice: Assessment, diagnosis, $\mathcal{E}^{2}$ therapy (3 $\left.{ }^{\text {rd }} \mathrm{ed}.\right)$. American Psychological Association.

Heimlich, (2011). Minorities account for nearly all U.S. population. Pew Research Center. growth. https:// www.pewresearch.org/fact-tank/2011/03/30/minorities-account-for-nearly-all-u-s-populationgrowth/

Holmes, J. A., \& Stevenson, C. A. (1990). Differential effects of avoidant and attentional coping strategies on adaptation to chronic and recent-onset pain. Health Psychology, 9, 577. https://doi. org/10.1037/0278-6133.9.5.577

Jackson, B. R., \& Bergeman, C. S. (2011). How does religiosity enhance wellbeing? The role of perceived control. Psychology of religion and spirituality, 3(2), 149-161. https://doi.org/10.1037/ a0021597

Jurcik, T., Ahmed, R., Yakobov, E., Solopieieva-Jurcikova, I., \& Ryder, A. G. (2013). Understanding the role of the ethnic density effect: Issues of acculturation, racial discrimination, and social support. Journal of Community Psychology, 41(6), 662-678. https://doi.org/10.1002/ jcop. 21563

Kayyali, R. (2013). US Census classifications and Arab Americans: contestations and definitions of identity markers. Journal of Ethnic and Migration Studies, 39(8), 1299-1318.

Kim, J., Han, J. Y., Shaw, B., McTavish, F., \& Gustafson, D. (2010). The roles of social support and coping strategies in predicting breast cancer patients' emotional wellbeing: testing mediation and moderation models. Journal of health psychology, 15(4), 543-552. https://doi. org/10.1177/1359105309355338

Krieger, N., \& Sidney, S. (1996). Racial discrimination and blood pressure: the CARDIA Study of young black and white adults. American journal of public health, 86(10), 1370-1378. https://doi. org/10.3410/f.1088626.542717

Krogstad, J.M., López, G. (2016). Roughly half of Hispanics have experienced racial discrimination. Pew Research Center. https://www.pewresearch.org/fact-tank/2016/06/29/roughly-half-ofhispanics-have-experienced-racial discrimination/

Kuiper, N. A., Grimshaw, M., Leite, C., \& Kirsh, G. (2004). Humor is not always the best medicine: Specific components of sense of humor and psychological wellbeing. Humor and Psychological Wellbeing, International Journal of Humor Research, 17(1-2), 135-168. https://doi.org/10.1515/ humr.2004.002

Martin, R. A., Puhlik-Doris, P., Larsen, G., Gray, J., \& Weir, K. (2003). Individual differences in uses of humor and their relation to psychological wellbeing: Development of the Humor 
Styles Questionnaire. Journal of research in personality, 37(1), 48-75. https://doi.org/10.1016/ s0092-6566(02)00534-2

Masci, D. (2019). Many Americans see religious racial discrimination in U.S. especially against Muslims. Pew Research Center. https:/www.pewresearch.org/fact-tank/2019/05/17/many-americanssee-religious-racial discrimination-in-u-s-especially-against-muslims/

Mason, J. (2018). Who are the Christian Arabs? Some Facts about Who they are and their Place in the World. Arab America. https://www.arabamerica.com/who-are-the-christian-arabs-somefacts-about-who-they-are-and-their-place-in-the-world/

Masten, A. S. (2001). Ordinary magic: Resilience processes in development. American psychologist, 56(3), 227-238. https://doi.org/10.1037/0003-066x.56.3.227

Masten, A. S., Burt, K. B., Roisman, G. I., Obradović, J., Long, J. D., \& Tellegen, A. (2004). Resources and resilience in the transition to adulthood: Continuity and change. Development and psychopathology, 16(4), 1071-1094. https://doi.org/10.1017/s0954579404040143

Min, J. A., Yu, J. J., Lee, C. U., \& Chae, J. H. (2013). Cognitive emotion regulation strategies contributing to resilience in patients with depression and/or anxiety disorders. Comprehensive psychiatry, 54(8), 1190-1197. https://doi.org/10.1016/j.comppsych.2013.05.008

Morrison, R., \& O'Connor, R. C. (2005). Predicting psychological distress in college students: The role of rumination and stress. Journal of clinical psychology, 61(4), 447-460. https://doi.org/10.1002/ jclp.20021

National Public Radio (2017). Racial discrimination in America: Experiences and views of Asian Americans. https://www.npr.org/assets/news/2017/12/racial discriminationpoll-asian-americans. pdf

Noh, S., \& Kaspar, V. (2003). Perceived racial discrimination and depression: Moderating effects of coping, acculturation, and ethnic support. American Journal of Public Health, 93(2), 232-238. https://doi.org/10.2105/ajph.93.2.232

Ntoumanis, N., Edmunds, J., \& Duda, J. L. (2009). Understanding the coping process from a selfdetermination theory perspective. British journal of health psychology, 14(2), 249-260. https://doi. org $/ 10.1348 / 135910708 \times 349352$

Olsson, C. A., Bond, L., Burns, J. M., Vella-Brodrick, D. A., \& Sawyer, S. M. (2003). Adolescent resilience: A concept analysis. Journal of adolescence, 26(1), 1-11. https://doi.org/10.1016/ j.pedn.2005.07.009

Padela, A. I., \& Heisler, M. (2010). The association of perceived abuse and racial discrimination after September 11, 2001, with psychological distress, level of happiness, and health status among Arab Americans. American Journal of Public Health, 100(2), 284-291. https://doi.org/10.2105/ ajph.2009.164954

Paradies, Y. (2006). A systematic review of empirical research on self-reported racism and health. International Journal of Epidemiology, 35(4), 888-901. https://doi.org/10.1093/ije/dy1056

Pérez, D. J., Fortuna, L., \& Alegria, M. (2008). Prevalence and correlates of everyday racial discrimination among US Latinos. Journal of community psychology, 36(4), 421. https://doi.org/10.1002/ jcop. 20221

Perreira, K. M., Fuligni, A., \& Potochnick, S. (2010). Fitting in: The roles of social acceptance and racial discrimination in shaping the academic motivations of Latino youth in the US Southeast. Journal of Social Issues, 66(1), 131-153. https://doi.org/10.1111/j.1540-4560.2009.01637.x

Pew Research Center (2017). U.S. Muslims Concerned About Their Place in Society, but Continue to Believe in the American Dream. https://www.scribbr.com/apa-examples/cite-a-website/ 
Phinney JS, Flores J. (2002). Unpacking acculturation: Aspects of acculturation as predictors of traditional sex role attitudes. Journal of Cross-Cultural Psychology, 33(3), 320-331. https://doi. org $/ 10.1177 / 0022022102033003007$

Puffer, E. S., Watt, M. H., Sikkema, K. J., Ogwang-Odhiambo, R. A., \& Broverman, S. A. (2012). The protective role of religious coping in adolescents' responses to poverty and sexual decisionmaking in rural Kenya. Journal of Research on Adolescence, 22(1), 1-7. https://doi.org/10.1111/ j.1532-7795.2011.00760.x

Rizzolo, D., Zipp, G. P., Stiskal, D., \& Simpkins, S. (2009). Stress management strategies for students: The immediate effects of yoga, humor, and reading on stress. Journal of College Teaching and Learning, 6(8), 79-88. https://doi.org/10.19030/tlc.v6i8.1117

Rogers, L. O., Zosuls, K. M., Halim, M. L., Ruble, D., Hughes, D., \& Fuligni, A. (2012). Meaning making in middle childhood: An exploration of the meaning of ethnic identity. Cultural Diversity and Ethnic Minority Psychology, 18(2), 99-108. Meaning making in middle childhood: An exploration of the meaning of ethnic identity.

Seaton, E. K., Caldwell, C. H., Sellers, R. M., \& Jackson, J. S. (2010). An intersectional approach for understanding perceived racial discrimination and psychological wellbeing among African American and Caribbean Black youth. Developmental psychology, 46(5), 1372-1379. https://doi. org/10.1037/a0019869

Schmitt, M. T., Branscombe, N. R., Postmes, T., \& Garcia, A. (2014). The consequences of perceived racial discrimination for psychological wellbeing: a meta-analytic review. Psychological Bulletin, 140(4), 921-948. https://doi.org/10.1037/a0035754

Schwartz, S. J., \& Unger, J. B. (2010). Biculturalism and Context: What Is Biculturalism, and When Is It Adaptive?, Human development, 53(1), 26-32. https://doi.org/10.1159/000268137

Skinner, E. A., \& Zimmer-Gembeck, M. J. (2007). The development of coping. Annual Review of Psychology, 58, 119-144. https://doi.org/10.1146/annurev.psych.58.110405.085705

Smith, J., Flowers, P., \& Larkin, M. (2009). Interpretative phenomenological analysis: Theory, method and research. Sage.

Smith, J. A., \& Osborn, M. (2007). Pain as an assault on the self: An interpretative phenomenological analysis of the psychological impact of chronic benign low back pain. Psychology and health, 22(5), 517-534. https://doi.org/10.1080/14768320600941756

Solorzano, D. G., \& Bernal, D. D. (2001). Examining transformational resistance through a critical race and LatCrit theory framework: Chicana and Chicano students in an urban context. Urban education, 36(3), 308-342. https://doi.org/10.1177/0042085901363002

Southern Poverty Law Center. (2017). Hate groups increase for second consecutive aery as Trump electrifies radical right. https://www.splcenter.org/news/2017/02/15/hate-groups-increase-second-consecutiveyear-trump-electrifies-radical-right

Starr \& Diamond. (2017). Trump launches military strike against Syria. CNN. https://www.cnn. com/2017/04/06/politics/donald-trump-syria-military/index.html

Sue, D. W., Capodilupo, C. M., Torino, G. C., Bucceri, J. M., Holder, A., Nadal, K. L., \& Esquilin, M. (2007). Racial microaggressions in everyday life: implications for clinical practice. American psychologist, 62(4), 271-286. https://doi.org/0.1037/0003-066X.62.4.271

Steinberg, L. (2005). Cognitive and affective development in adolescence. Trends in cognitive sciences, 9(2), 69-74. https://doi.org/10.1016/j.tics.2004.12.005

Steinhardt, M., \& Dolbier, C. (2008). Evaluation of a resilience intervention to enhance coping strategies and protective factors and decrease symptomatology. Journal of American college health, 56(4), 445-453. https://doi.org/10.3200/jach.56.44.445-454 
Torres, L., \& Ong, A. D. (2010). A daily diary investigation of Latino ethnic identity, racial discrimination, and depression. Cultural Diversity and Ethnic Minority Psychology, 16(4), 561-568. https://doi.org/10.1037/a0020652

Totenberg \& Montanro. (2018). In Big Win For White House, Supreme Court Upholds President Trump's Travel Ban. https://www.npr.org/2018/06/26/606481548/supreme-court-upholds-trumptravel-ban

Tugade, M. M., Fredrickson, B. L., \& Feldman Barrett, L. (2004). Psychological resilience and positive emotional granularity: Examining the benefits of positive emotions on coping 266 and health. Journal of personality, 72(6), 1161-1190. https://doi.org/10.1111/j.1467-6494.2004.00294.x

Tynes, B. M., Giang, M. T., Williams, D. R., \& Thompson, G. N. (2008). Online racial discrimination and psychological adjustment among adolescents. Journal of Adolescent Health, 43(6), 565-569. https://doi.org/10.1016/j.jadohealth.2008.08.021

Umaña-Taylor, A. J., Tynes, B. M., Toomey, R. B., Williams, D. R., \& Mitchell, K. J. (2015). Latino adolescents' perceived racial discrimination in online and offline settings: An examination of cultural risk and protective factors. Developmental psychology, 51(1), 87-100. https://doi.org/10.1037/ a0038432

United States Census Bureau. (2019). American Community Survey. https://www.census.gov/acs/www/ data/data-tables-and-tools/data-profiles/2018/

Wexler, L. M., DiFluvio, G., \& Burke, T. K. (2009). Resilience and marginalized youth: Making a case for personal and collective meaning-making as part of resilience research in public health. Social science E medicine, 69(4), 565-570. https://doi.org/10.1016/j.socscimed.2009.06.022

Wong, C. A., Eccles, J. S., \& Sameroff, A. (2003). The influence of ethnic racial discrimination and ethnic identification on African American adolescents' school and socioemotional adjustment. Journal of personality, 71(6), 1197-1232. https://doi.org/10.1111/1467-6494.7106012

$\mathrm{Xu}, \mathrm{J} .$, \& He, Y. (2012). Psychological health and coping strategy among survivors in the year following the 2008 Wenchuan earthquake. Psychiatry and Clinical Neurosciences, 66(3), 210-219. https://doi. org $/ 10.1111 / \mathrm{j} .1440-1819.2012 .02331 . \mathrm{x}$ 